\title{
Photoelectron and threshold photoelectron valence spectra of pyridine
}

\author{
Małgorzata A. Śmiałek ${ }^{1,4, a}$, Michael A. MacDonald ${ }^{2}$, Sylwia Ptasińska ${ }^{3}$, Lucia Zuin ${ }^{2}$, and Nigel J. Mason ${ }^{4}$ \\ 1 Department of Control and Power Engineering, Faculty of Ocean Engineering and Ship Technology, Gdansk University \\ of Technology, Gabriela Narutowicza 11/12, 80-233 Gdansk, Poland \\ 2 Canadian Light Source Inc., 44 Innovation Boulevard, Saskatoon SK S7N 2V3, Canada \\ 3 Radiation Laboratory and Department of Physics, University of Notre Dame, Notre Dame, 46556, IN, USA \\ 4 Department of Physical Sciences, The Open University, Walton Hall, Milton Keynes MK7 6AA, UK
}

Received 26 November 2015 / Received in final form 22 December 2015

Published online 25 February 2016

(c) The Author(s) 2016. This article is published with open access at Springerlink.com

\begin{abstract}
The pyridine molecule has been examined by the means of photoelectron and threshold photoelectron spectroscopies. Ionization energies were determined for both outer and inner valence orbitals and new adiabatic values were also resolved. Vibronic structure associated with several states was assigned mainly to be due to $\mathrm{C}-\mathrm{C}$ stretches and ring bends. Additionally a Rydberg state converging to $7 \mathrm{~b}_{2}$ state was ascribed. The data shown here are in a good agreement with previous results and brings some new insights into the electronic structure of this biologically and astrochemically relevant and important molecule.
\end{abstract}

\section{Introduction}

Pyridine molecule, shown in Figure 1, was chosen as the subject of this study. This molecule is often used as a precursor to agrochemicals (bacteri- and herbicides) and medicines (sulfapyridine or tripelennamine) [1] and also utilized as a solvent or chemical reagent [2]. Many chemicals contain pyridine ring structure, like B-group vitamins or nicotine [3]. Investigations of this molecule are thus not only important due to its industrial or biological implications but are also valid for astrochemistry, since it has been shown that B-group vitamins [4] can be found on the surface of meteorites [5].

This simple aromatic azabenzene has been extensively studied in the past with respect to both its vibrational [6-8] and electronic structure [9] by experimental [10-14] and computational [15-18] approaches. Moreover, low-lying Rydberg states have also been examined for this molecule $[19,20]$. From the abovementioned studies it was concluded that the HOMO in pyridine is of $n$-type. Introducing the nitrogen atom into the benzene ring causes perturbation in the energy levels and thus some new transitions are available in pyridine that are due to the lone-pair electrons $[13,21]$.

\footnotetext{
* Contribution to the Topical Issue "Advances in Positron and Electron Scattering", edited by Paulo Limao-Vieira, Gustavo Garcia, E. Krishnakumar, James Sullivan, Hajime Tanuma and Zoran Petrovic.

a e-mail: smialek@pg.gda.pl
}

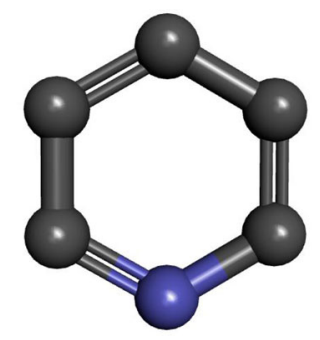

Fig. 1. Pyridine molecule; gray indicates carbon atoms, blue indicates nitrogen substituting one of the methine groups of benzene ring.

Also, photoionization and fragmentation of this molecule have been studied in the $8-30 \mathrm{eV}$ range indicating that there is a significant bond rearrangement and nuclear motion during dissociation, since relative fragment yields formed upon varying excitation energy differ significantly [22]. Recently, it was found that dissociation of pyridine may occur via ring opening and isomerization mechanisms [23].

In this work we focused on photoelectron (PES) and threshold photoelectron (TPES) spectroscopic studies of the pyridine molecule. Using a high resolution photoelectron spectrometer, described later, it was possible not only to resolve the inner and outer valence ionization energies, but also, throughout the threshold electron measurements, confirm the vibronic structure associated with most of the bands in the spectrum. 


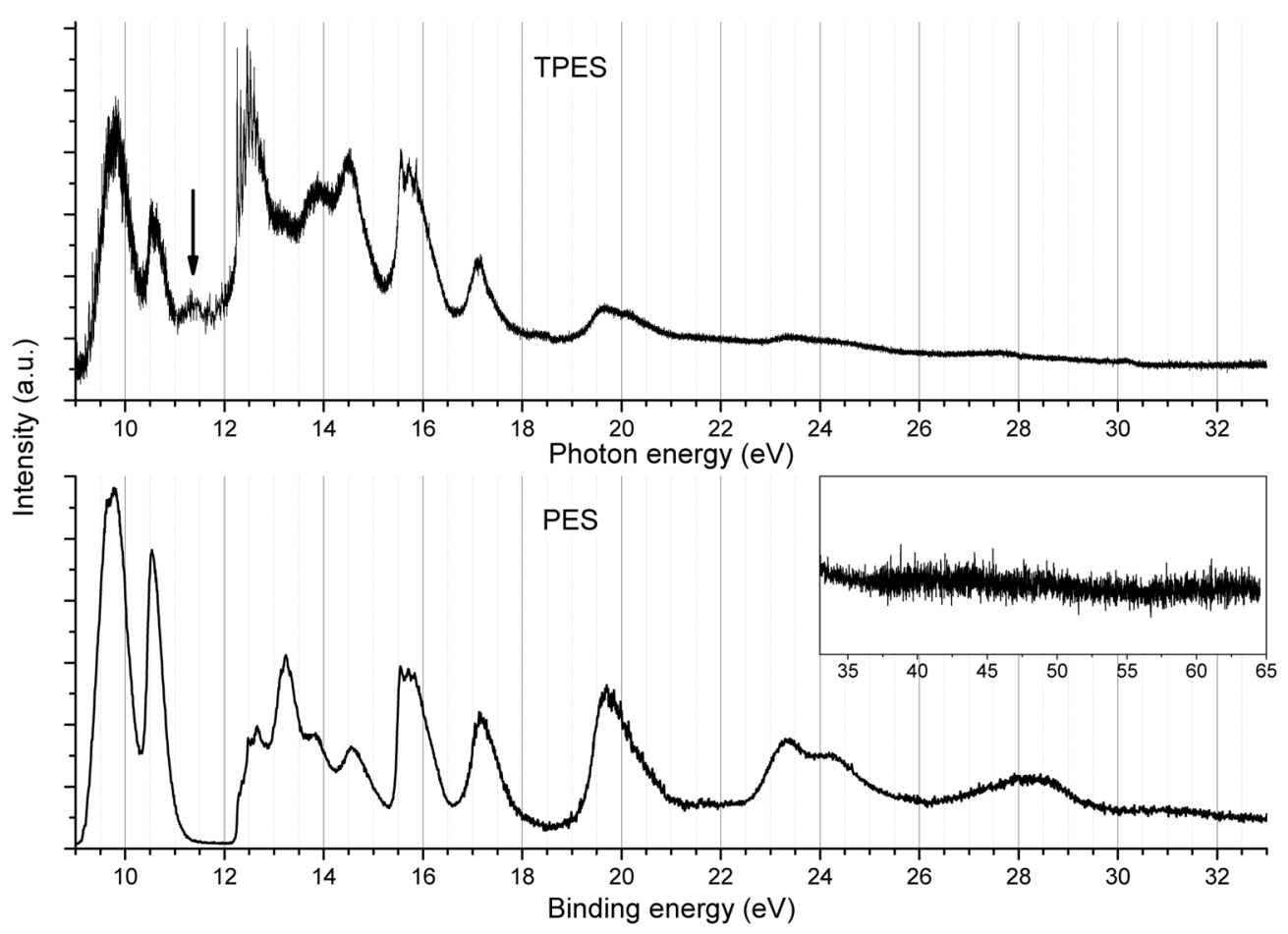

Fig. 2. Complete valence shell photoelectron spectra of pyridine recorded at (top) thresholds and (bottom) $80 \mathrm{eV}$ incident photon energy; the insert in PES shows $33-65 \mathrm{eV}$ binding energy range, obtained at $100 \mathrm{eV}$ incident photon energy; see text for further details.

\section{Materials and methods}

\subsection{Pyridine sample}

Pyridine sample of purity higher than $99.9 \%$ was purchased from Sigma-Aldrich, Canada, and used with no further processing. In order to introduce the sample into the UHV system, pyridine (liquid) was transferred into a stainless steel container and degassed in four freeze-thawpump cycles.

\subsection{Threshold and photoelectron spectra}

Both the threshold photoelectron and photoelectron spectra of pyridine (Fig. 2) were recorded at the VLS-PGM beamline [24], at the Canadian Light Source facility in Saskatoon, Canada, using a Double Toroidal Coincidence Spectrometer. The apparatus was described previously in detail [25] and a specific description of the operation in the threshold mode was also provided [26]. Although it was primarily designed to be used for measurements of noble gases and small, diatomic molecules, it was recently proven that it may also be used for measurements on more complicated systems, such as pyrimidine and of its heavier derivatives [27] or esters [28,29].

Briefly, a photoelectron-photoelectron coincidence spectrometer allows for the two electrons, of specified energies, to be detected over a wide range of emission angles. The spectrometer is based on a toroidal geometry and has properties ideally suited for measuring electron angle distributions, since toroidal analysers can be made to energy-select the photoelectrons while preserving the initial angle of emission. The spectrometer consists of two toroidal analyzers, each focused on the interaction region. One collects electrons over an azimuthal range of $180^{\circ}$, the other over $120^{\circ}$. These electrostatic analyzers are independent, i.e., they are able to detect dissimilar electron energies, with different resolutions.

For photoelectron spectra measurements, both analyzers were set to a pass energy of $4 \mathrm{eV}$. The analysis was performed for the data collected by the $180^{\circ}$ toroidal detector. Spectra shown here were calibrated against the $\mathrm{X}^{2} \Sigma_{g}^{+}$, $\nu^{\prime}=0$ and $\mathrm{A}^{2} \Pi_{u}, \nu^{\prime}=0$ peaks of $\mathrm{N}_{2}^{+}$, rounded to three decimal places [30,31], introduced to the chamber together with the pyridine sample. The measured resolution from the nitrogen calibration spectra was $60 \mathrm{meV}$. The photoexcitation energy for the photoelectron spectrum presented here was $80 \mathrm{eV}$ in the $0-33 \mathrm{eV}$ region and $100 \mathrm{eV}$ for $33-65 \mathrm{eV}$ photoelectrons, recorded with the entrance and exit slits of the VLS-PGM beamline set at $50 \mu \mathrm{m}$.

For the threshold photoelectron spectra measurements only the $120^{\circ}$ toroidal detector was used. The detector was set to collect near-zero-eV electrons and the resolution was determined against the $\operatorname{Ar}{ }^{2} \mathrm{P}_{3 / 2}$ and ${ }^{2} \mathrm{P}_{1 / 2}$ lines to yield $7 \mathrm{meV}$. Spectra were normalized to the incident photon flux. No evidence of significant higher order contamination in the TPES spectra was seen. Specifically, there is no vibrationally-resolved structure above $20 \mathrm{eV}$, which would be reflected in the nominal PES around $10 \mathrm{eV}$. 


\section{Results and discussion}

From the photoelectron spectrum shown in Figure 2 it was possible to assign all the ionization energies for the inner and outer valence orbitals of the pyridine molecule. The adiabatic and vertical values were obtained through the Gaussian function fitting procedure and are summarized in Table 1, together with the values obtained from the literature. The fitting was performed using Origin Pro 2015 software and the obtained results were at the level of $10 \%$ with respect to the values of residuals. Vertical values are marked with lines on the PES spectra in Figures 3-7, bottom panels. The nomenclature for labelling the states followed that proposed by Clementi [9], although various authors have different recommendations for the order of the molecular orbitals (see for example Moghaddam et al. [17]). The data presented here is not only in an excellent agreement with the previous results, but also, due to high resolution of present experiment, it was possible to assign some new adiabatic ionization energies and resolve bands that previously appeared as one feature.

This was achieved with assistance of measured TPES, shown in Figures 2-7 in the top panels. TPES measurements allowed resolving the vibronic structure associated with most of the ionization energies as well as to assign a possible Rydberg state. These assignments are shown in Figures 3-7 and summarised in Tables 2-4.

A very thorough review by Innes et al. [32] on azabenzenes gives a summary of 27 fundamental vibrational frequencies that can be assigned in pyridine spectrum. From there, Reineck et al. concluded that in the photoelectron spectrum, only the fully symmetric vibrational modes are expected to be strongly excited, and thus only ten of them are of potential interest. In our spectra we also found the series that could not have been assigned to those ten modes due to discrepancies in energy values, therefore, we also used assignments proposed by Partal Urena et al. [7]. In their work additional combinations of vibrational modes were assigned. Table 2 shows the vibrational modes assigned in the spectra presented here (marked in bold in the text).

Over the first band, that consists of the $11 \mathrm{a}_{1}$ and $1 \mathrm{a}_{2}$ states it was possible to ascribe a rich vibronic structure associated with the first IE to a combination of modes: 1 (C-C stretch) and $\mathbf{6 a}$ (in-plane ring bend). It should be noted that the obtained values of electron binding energy for all higher electronic states are in an excellent agreement with values given by Reineck et al. [12] and those of Liu et al. [14] that were obtained by a sophisticated photoelectron imaging spectrometer. Also, the value of adiabatic ionization energy, $9.197 \mathrm{eV}$, is in an excellent agreement with values reported by Liu et al. [14] (9.199 eV), Reineck et al. [12] (9.197 eV) and Riese et al. [33] (9.198 eV). The latter obtained this value through mass-ionized threshold ionization spectroscopy studies.

The position of the vertical ionization energy of the second electronic state of the ion was assigned to be $9.855 \mathrm{eV}$ and also one quantum of the $\mathbf{1}$ mode can be distinguished on the shoulder of the band.

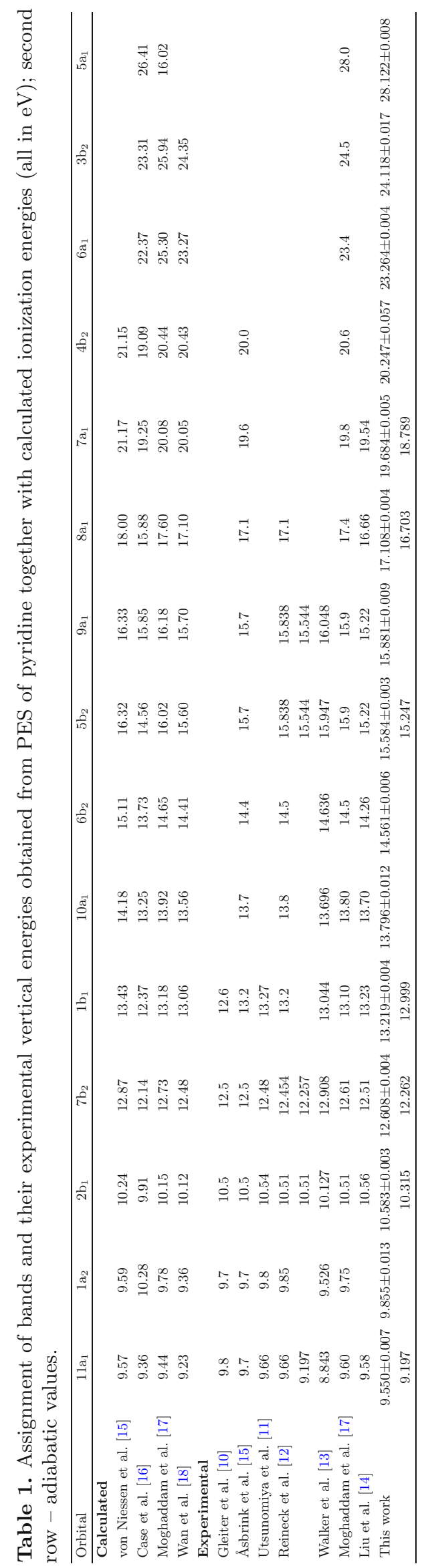




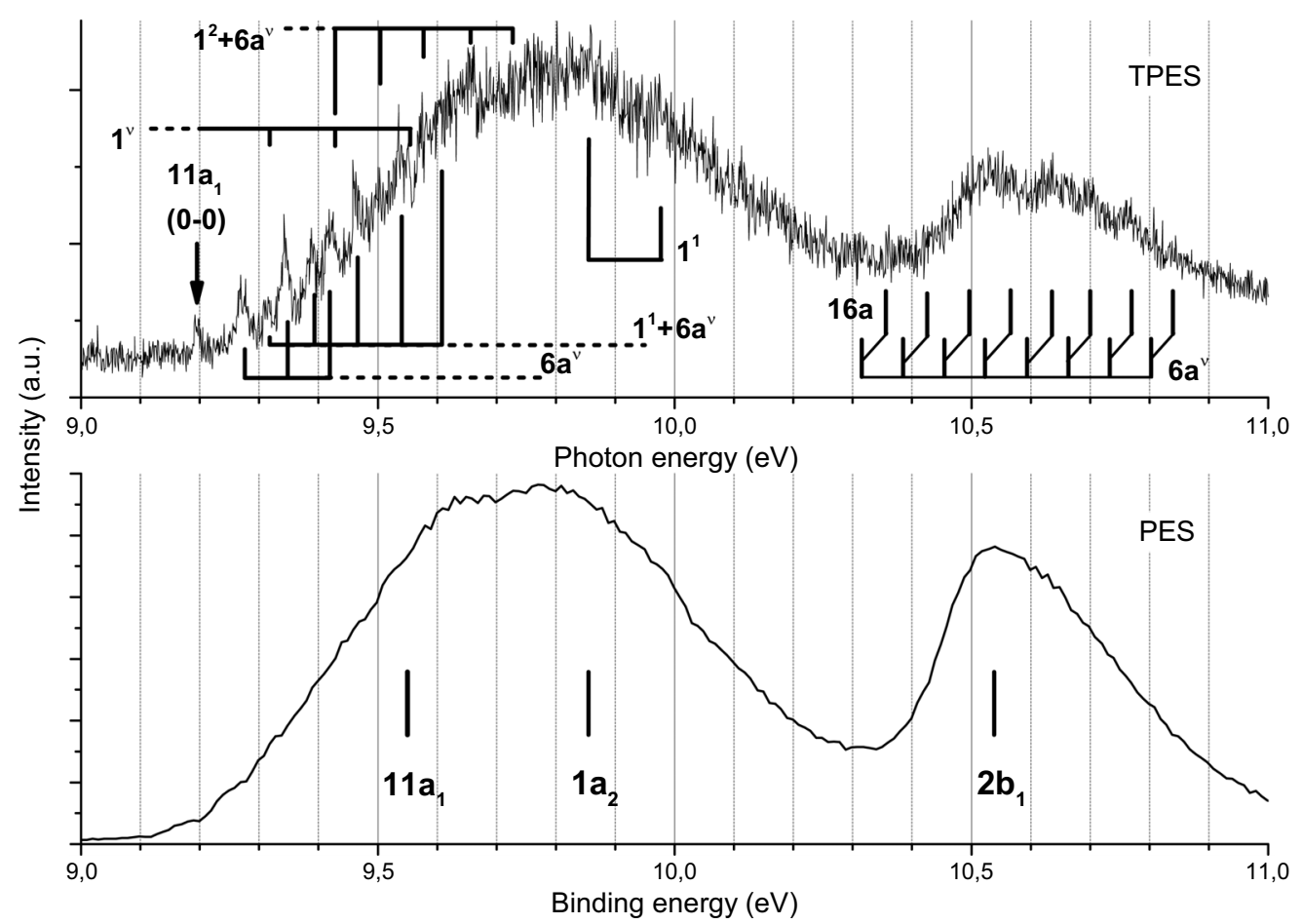

Fig. 3. Valence shell photoelectron spectra of pyridine recorded at (top) thresholds and (bottom) 80 eV incident photon energy in the energy range of 9-11 eV.

Table 2. Vibrational modes (Wilson's notation) [7,32] and their energies found in the pyridine spectrum.

\begin{tabular}{ccc}
\hline Mode & Desctiption & Energy $(\mathrm{meV})$ \\
\hline $16 \mathrm{~b}$ & out-of-plane ring bend & 31 \\
$16 \mathrm{a}$ & out-of-plane ring bend & 41 \\
$6 \mathrm{a}$ & in-plane ring bend & 70 \\
1 & carbon-carbon stretch & 116 \\
$18 \mathrm{a}$ & in-plane C-H bend & 152 \\
14 & carbon-carbon stretch & 161 \\
$8 \mathrm{a}$ & carbon-carbon stretch & 204 \\
$(16 \mathrm{a}+3)$ & out-of-plane ring bend with in-plane C-H bend & 214 \\
$(8 \mathrm{a}+12)$ & C-C stretch with in-plane ring bend & 240 \\
\hline
\end{tabular}

On the third electronic state of the ion, $2 \mathrm{~b}_{1}$, a combination of $\mathbf{1 6 a}$ (both out-of-plane ring bend) and $\mathbf{6 a}$ modes was resolved, with the adiabatic value found at $10.315 \mathrm{eV}$.

The feature visible only in the TPES, centred at the $11.325 \mathrm{eV}$, marked in Figure 2 (top) with an arrow, can be assigned to a $4 s$ Rydberg state, converging to the $7 \mathrm{~b}_{2}$ ionization energy. The quantum defect, $\delta=0.74$, is within the same range with the value obtained by others for the $n s$ transitions converging to the $11 \mathrm{a}_{1}$ state $(\delta=0.85)$ [20].

In Figure 4 the band consisting of four ionization energies: $7 b_{2}, 1 b_{1}, 10 a_{1}$ and $6 b_{2}$, is presented. Additionally, in the band of $7 b_{2}$ state, a vibronic structure consisting of combination of mode $\mathbf{8}$ (C-C stretch) with modes $\mathbf{1 8 a}$ (in-plane $\mathrm{CH}$ bend) and $\mathbf{6 a}$ can be resolved. These results are also in a good agreement with the ones shown previously [12]. Over the $1 b_{1}$ band, three quanta of mode $\mathbf{1}$ can be seen in both the PES and TPES spectra. The adiabatic ionization energies found for these two states yielded $12.262 \mathrm{eV}$ and $12.999 \mathrm{eV}$, respectively. For the $10 \mathrm{a}_{1}$ and

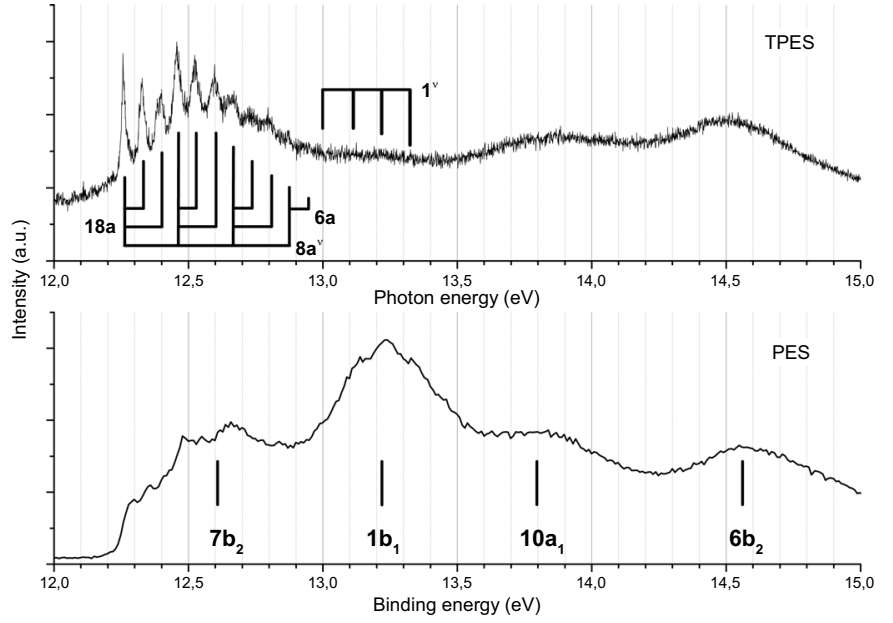

Fig. 4. Valence shell photoelectron spectra of pyridine recorded at (top) thresholds and (bottom) $80 \mathrm{eV}$ incident photon energy in an energy range of $12-15 \mathrm{eV}$. 
Table 3. Binding energies of Rydberg and vibrational assignments of bands in pyridine spectrum.

\begin{tabular}{|c|c|c|c|c|}
\hline Binding energy $(\mathrm{eV})$ & Assignment & Utsunomiya et al. [11] & Reineck et al. [12] & Liu et al. [14] \\
\hline \multicolumn{5}{|l|}{$11 \mathrm{a}_{1}$ (Fig. 3) } \\
\hline 9.199 & $0-0$ & - & 9.197 & 9.199 \\
\hline 9.276 & $6 \mathrm{a}$ & 9.26 & 9.271 & 9.273 \\
\hline 9.318 & 1 & - & 9.319 & 9.318 \\
\hline 9.348 & $6 a^{2}$ & 9.36 & 9.346 & 9.348 \\
\hline 9.393 & $1+6 \mathrm{a}$ & - & 9.391 & 9.3925 \\
\hline 9.419 & $6 \mathrm{a}^{3}$ & - & 9.421 & 9.419 \\
\hline 9.428 & $1^{2}$ & 9.46 & - & 9.428 \\
\hline 9.466 & $1+6 a^{2}$ & - & 9.465 & 9.467 \\
\hline 9.504 & $1^{2}+6 \mathrm{a}$ & - & - & 9.504 \\
\hline 9.540 & $1+6 \mathrm{a}^{3}$ & - & 9.536 & 9.541 \\
\hline 9.555 & $1^{3}$ & 9.56 & - & 9.555 \\
\hline 9.577 & $1^{2}+6 a^{2}$ & - & 9.580 & 9.579 \\
\hline 9.608 & $1+6 a^{4}$ & - & 9.608 & 9.610 \\
\hline 9.656 & $1^{2}+6 \mathrm{a}^{3}$ & 9.66 & 9.657 & 9.644 \\
\hline \multicolumn{5}{|l|}{$1 \mathrm{a}_{2}$ (Fig. 3) } \\
\hline 9.855 & Vertical IE & 9.80 & 9.85 & - \\
\hline 9.977 & 1 & 9.90 & 9.97 & - \\
\hline \multicolumn{5}{|l|}{$2 b_{1}$ (Fig. 3) } \\
\hline 10.351 & $0-0$ & - & - & - \\
\hline 10.356 & $16 \mathrm{a}$ & - & - & - \\
\hline 10.385 & $6 \mathrm{a}$ & - & - & - \\
\hline 10.425 & $6 a+16 a$ & - & - & - \\
\hline 10.455 & $6 \mathrm{a}^{2}$ & - & - & - \\
\hline 10.496 & $6 a^{2}+16 a$ & - & - & - \\
\hline 10.522 & $6 \mathrm{a}^{3}$ & - & - & - \\
\hline 10.566 & $6 a^{3}+16 a$ & - & - & - \\
\hline 10.594 & $6 a^{4}$ & - & - & - \\
\hline 10.636 & $6 \mathrm{a}^{4}+16 \mathrm{a}$ & - & - & - \\
\hline 10.663 & $6 \mathrm{a}^{5}$ & - & - & - \\
\hline 10.699 & $6 a^{5}+16 a$ & - & - & - \\
\hline 10.733 & $6 \mathrm{a}^{6}$ & - & - & - \\
\hline 10.770 & $6 \mathrm{a}^{6}+16 \mathrm{a}$ & - & - & - \\
\hline 10.801 & $6 \mathrm{a}^{7}$ & - & - & - \\
\hline 10.841 & $6 a^{7}+16 a$ & - & - & - \\
\hline \multicolumn{5}{|l|}{$7 b_{2}$ (Fig. 4) } \\
\hline 11.325 (Fig.2) & $4 s\left(7 \mathrm{~b}_{2}\right), \delta=0.74$ & - & - & - \\
\hline 12.262 & $0-0$ & - & 12.285 & - \\
\hline 12.332 & $6 \mathrm{a}$ & - & 12.349 & - \\
\hline 12.401 & $18 \mathrm{a}$ & - & 12.392 & - \\
\hline 12.463 & $8 \mathrm{a}$ & - & 12.478 & - \\
\hline 12.529 & $8 a+6 a$ & - & 12.549 & - \\
\hline 12.602 & $8 a+18 a$ & - & 12.580 & - \\
\hline 12.667 & $8 a^{2}$ & - & - & - \\
\hline 12.736 & $8 a^{2}+6 a$ & - & - & - \\
\hline 12.802 & $8 a^{2}+18 a$ & - & - & - \\
\hline 12.875 & $8 a^{3}$ & - & - & - \\
\hline 12.946 & $8 a^{3}+6 a$ & - & - & - \\
\hline \multicolumn{5}{|l|}{ 1b $b_{1}$ (Fig. 4) } \\
\hline 12.999 & $0-0$ & - & 13.081 & - \\
\hline 13.114 & 1 & - & 13.207 & - \\
\hline 13.219 & $1^{2}$ & - & 13.317 & - \\
\hline 13.324 & $1^{3}$ & - & - & - \\
\hline
\end{tabular}


Table 4. Binding energies of vibrational assignments of bands in pyridine spectrum; asterisks marks tentative assignments, star marks a combined mode from reference [7].

\begin{tabular}{lc}
\hline Binding energy $(\mathrm{eV})$ & Assignment \\
\hline $5 \mathrm{~b}_{2}$ (Fig. 5) & $0-0$ \\
15.247 & $16 \mathrm{~b}$ \\
15.410 & $16 \mathrm{~b}^{2}$ \\
15.563 & $16 \mathrm{~b}^{2}+14$ \\
15.601 & $16 \mathrm{~b}^{3}$ \\
15.726 & $16 \mathrm{~b}^{3}+14$ \\
15.762 & \\
$9 \mathrm{a}_{1}($ Fig. 5$)$ & \\
15.871 & $(8 \mathrm{a}+12)(\star)$ \\
16.122 & \\
$8 \mathrm{a}_{1}($ Fig. 5$)$ & $0-0$ \\
16.703 & $(8 \mathrm{a}+12)(\star)$ \\
16.938 & $(8 \mathrm{a}+12)+1(\star)$ \\
17.062 & $(8 \mathrm{a}+12)^{2}(\star)$ \\
17.168 & $(8 \mathrm{a}+12)^{3}(\star)$ \\
17.403 & \\
$7 \mathrm{a}_{1}($ Fig. 6$)$ & $0-0$ \\
18.789 & $(16 \mathrm{a}+3)(\star)$ \\
$19.043^{*}$ & $(16 \mathrm{a}+3)^{2}(\star)$ \\
$19.257^{*}$ & $(16 \mathrm{a}+3)^{3}(\star)$ \\
19.468 & $(16 \mathrm{a}+3)^{4}(\star)$ \\
19.684 & $(16 \mathrm{a}+3)^{5}(\star)$ \\
19.896 & $(16 \mathrm{a}+3)^{6}(\star)$ \\
20.109 &
\end{tabular}

$6 \mathrm{~b}_{2}$ states it was only possible to obtain the vertical values of $13.796 \mathrm{eV}$ and $14.561 \mathrm{eV}$, respectively.

There are two bands shown in Figure 5. In the first one, two ionization energies from orbitals $5 \mathrm{~b}_{2}$ and $9 \mathrm{a}_{1}$ can be distinguished. Further, a mode 16b (out-of-plane ring bend) combined with one quantum of mode 14 (C-C stretch) was resolved over $5 \mathrm{~b}_{2}$ state. This structure was not resolved previously and provided an adiabatic value for ionization of $15.247 \mathrm{eV}$. The ionization from the $9 \mathrm{a}_{1}$ state can be associated with one mode of $(8 \mathbf{a}+\mathbf{1 2})$ that is an in-plane ring bend associated with a $\mathrm{C}-\mathrm{C}$ stretch, according to the findings of Partal Urena et al. [7]. The second band is due to ionization from $8 a_{1}$ orbital. The ionization energy in this band is accompanied by three quanta of the combined $(\mathbf{8} \mathbf{a}+\mathbf{1 2})$ mode and one quantum of mode $\mathbf{1}$. Here, it was also possible for the first time to assign the adiabatic value for ionization from the $8 \mathrm{a}_{1}$ orbital of $16.703 \mathrm{eV}$.

In Figure 6 there is only one band that is due to two ionization energies from the orbitals $7 a_{1}$ and $4 b_{2}$. There is also a vibronic progression associated with the former that can be attributed to six quanta of a combined mode $(\mathbf{1 6 a}+\mathbf{3})$, which is an out-of-plane ring bend mixed with in-plane $\mathrm{CH}$ bend. Thus, it was possible to assign an adiabatic value of $18.789 \mathrm{eV}$ for the $7 \mathrm{a}_{1}$ state, whereas for the $4 b_{2}$ only the vertical value of $20.247 \mathrm{eV}$ could be established.

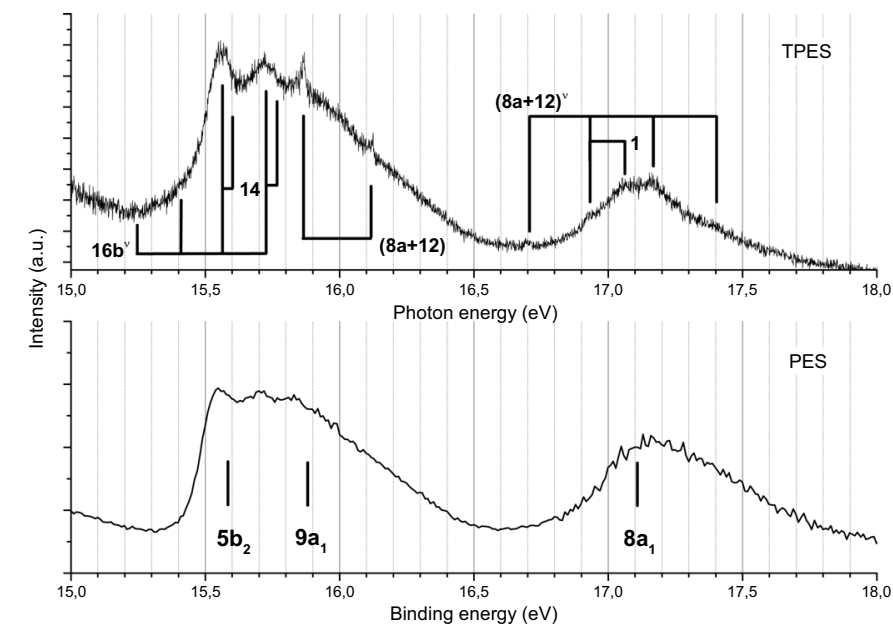

Fig. 5. Valence shell photoelectron spectra of pyridine recorded at (top) thresholds and (bottom) $80 \mathrm{eV}$ incident photon energy in an energy range of $15-18 \mathrm{eV}$.

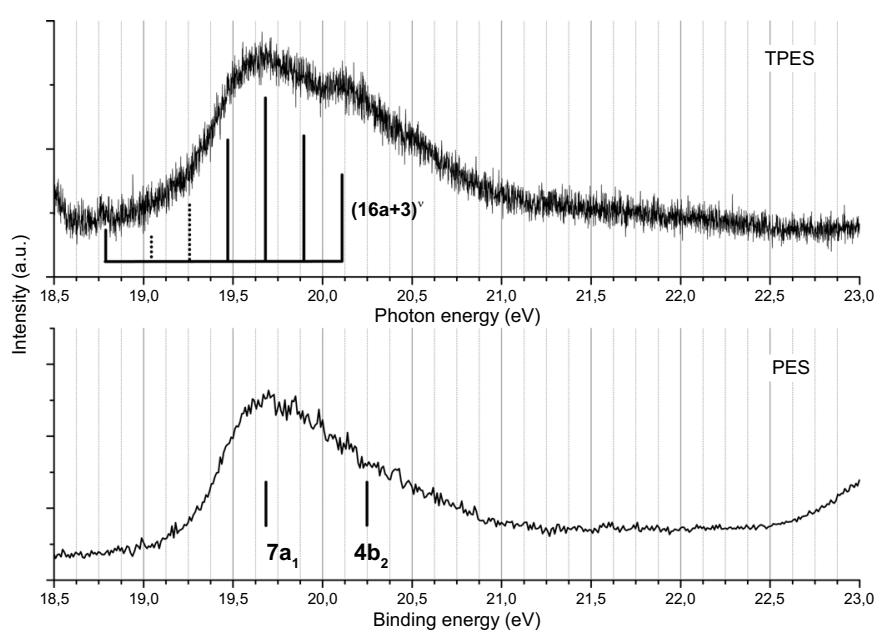

Fig. 6. Valence shell photoelectron spectra of pyridine recorded at (top) thresholds and (bottom) $80 \mathrm{eV}$ incident photon energy in an energy range of $18.5-23 \mathrm{eV}$; dotted lines mark a tentative assignment.

A broad double peak, seen in Figure 7, was determined to be a result of ionization from the $6 \mathrm{a}_{1}$ and $3 \mathrm{~b}_{2}$ orbitals with vertical values of $23.264 \mathrm{eV}$ and $24.118 \mathrm{eV}$, respectively. There are also additional two peaks visible in the PES in Figure 7. The first one is due to ionization from the $5 \mathrm{a}_{1}$ orbital at $28.122 \mathrm{eV}$. As it was shown through computational methods [18], the features observed in the PES above the binding energy of $25 \mathrm{eV}$ are strongly influenced by multielectron processes (MEP) and thus we ascribed the band centered around $31.2 \mathrm{eV}$ to be due to such interactions. A slight increase in the photoionization efficiency at this energy was also observed by others [34]. In the TPES there are other distinguished features in the range of $29-31 \mathrm{eV}$ that were attributed to the pressure fluctuations during this measurement. 


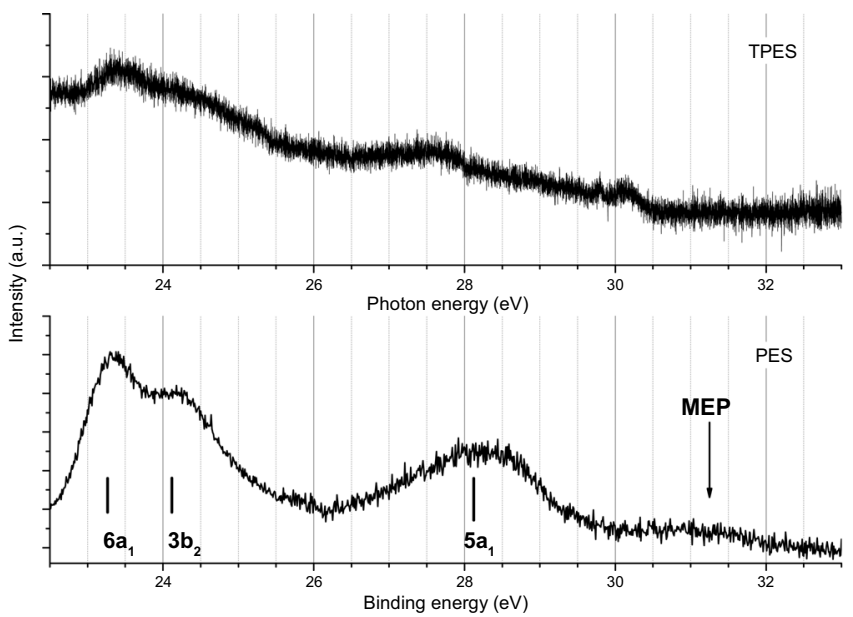

Fig. 7. The valence shell photoelectron spectra of pyridine recorded at (top) thresholds and (bottom) $80 \mathrm{eV}$ incident photon energy in an energy range of $22.5-33 \mathrm{eV}$.

\section{Conclusions}

In this work we revisited on the subject of photoelectron spectroscopy investigations of the pyridine molecule. Using a high resolution photoelectron spectrometer, it was possible not only to resolve the inner and outer valence ionization energies, but also, throughout the threshold electron measurements, confirm the vibronic structure associated with most of the bands in the spectrum. This vibronic structure associated with several states was assigned mainly to be due to $\mathrm{C}-\mathrm{C}$ stretches and ring bends. Additionally, a possible Rydberg state, converging to $7 \mathrm{~b}_{2}$ state, was ascribed. The data shown here are in an excellent agreement with previous results and brings some new insights into the electronic structure of pyridine molecule.

Research described in this paper was performed at the Canadian Light Source, which is supported by the Canada Foundation for Innovation, Natural Sciences and Engineering Research Council of Canada, the University of Saskatchewan, the Government of Saskatchewan, Western Economic Diversification Canada, the National Research Council Canada, and the Canadian Institutes of Health Research.

\section{References}

1. W. M, Arch. Dermatol. 87, 489 (1963)

2. J. Jankolovits, J.W. Kampf, V.L. Pecoraro, Inorg. Chem. 53, $7534(2014)$

3. R.T. Burns, J.A. Pechenik, W.J. Biggers, G. Scavo, C. Lehman, PLoS One 9, e109535 (2014)

4. H. Waisman, C. Elvehjem, Ind. Eng. Chem. Anal. Ed. 13, $221(1941)$

5. P.G. Stoks, A.W. Schwartz, Geochim. Cosmochim. Acta 45, 563 (1981)

6. T. Klots, Spectrochim. Acta Part A 54, 1481 (1998)

7. F. Partal Urena, M. Fernández Gómez, J. López González, E. Martínez Torres, Spectrochim. Acta Part A 59, 2815 (2003)
8. M. Szafran, J. Koput, J. Mol. Struct. 565-566, 439 (2001)

9. E. Clementi, J. Chem. Phys. 46, 4731 (1967)

10. R. Gleiter, E. Heilbronner, V. Hornung, Helv. Chim. Acta 55, 255 (1972)

11. C. Utsunomiya, T. Kobayashi, S. Nagakura, Bull. Chem. Soc. Jpn 51, 3482 (1978)

12. I. Reineck, R. Maripuu, H. Veenhuizen, L. Karlsson, K. Siegbahn, M. Powar, W.N. Zu, J.M. Rong, S. AlShamma, J. Electron Spectrosc. Relat. Phenom. 27, 15 (1982)

13. I. Walker, M. Palmer, A. Hopkirk, Chem. Phys. 141, 365 (1990)

14. S.Y. Liu, K. Alnama, J. Matsumoto, K. Nishizawa, H. Kohguchi, Y.P. Lee, T. Suzuki, J. Phys. Chem. A 115, 2953 (2011)

15. W. von Niessen, G. Diercksen, L. Cederbaum, Chem. Phys. 10, $345(1975)$

16. D.A. Case, M. Cook, M. Karplus, J. Chem. Phys. 73, 3294 (1980)

17. M.S. Moghaddam, A. Bawagan, K. Tan, W. von Niessen, Chem. Phys. 207, 19 (1996)

18. J. Wan, M. Hada, M. Ehara, H. Nakatsuji, J. Chem. Phys, 114, 5117 (2001)

19. C.F. Dion, E.R. Bernstein, J. Chem. Phys. 103, 4907 (1995)

20. M. Tsubouchi, T. Suzuki, J. Phys. Chem. A 107, 10897 (2003)

21. A. Bolovinos, P. Tsekeris, J. Philis, E. Pantos, G. Andritsopoulos, J. Mol. Spectrosc. 103, 240 (1984)

22. G. Vall-llosera, M. Coreno, P. Erman, M. Huels, K. Jakubowska, A. Kivimäki, E. Rachlew, M. Stankiewicz, Int. J. Mass Spectrom. 275, 55 (2008)

23. T.J. Wasowicz, A. Kivimäki, M. Coreno, M. Zubek, J. Phys. B 47, 055103 (2014)

24. Y.F. Hu et al., Rev. Sci. Instrum. 78, 083109 (2007)

25. T. Reddish, G. Richmond, G. Bagley, J. Wightman, S. Cvejanovic, Rev. Sci. Instrum. 68, 2685 (1997)

26. A.E. Slattery, J.P. Wightman, M.A. MacDonald, S. Cvejanovic, T.J. Reddish, J. Phys. B 33, 4833 (2000)

27. M. Śmiałek, E. Szymańska, M. MacDonald, L. Zuin, N. Mason, Eur. Phys. J. Special Top. 222, 2361 (2013)

28. M.A. Smialek, M. Labuda, J. Guthmuller, M.J. HubinFranskin, J. Delwiche, D. Duflot, N.J. Mason, S.V. Hoffmann, N.C. Jones, P. Limao-Vieira, J. Chem. Phys. 141, 104311 (2014)

29. M.A. Śmiałek, M. Łabuda, J. Guthmuller, S.V. Hoffmann, N.C. Jones, M.A. MacDonald, L. Zuin, N.J. Mason, P. Limao-Vieira, J. Phys. Chem. A 119, 8647 (2015)

30. K. Huber, C. Jungen, J. Chem. Phys. 92, 850 (1990)

31. D. Shaw, D. Holland, M. MacDonald, A. Hopkirk, M. Hayes, S. McSweeney, Chem. Phys. 166, 379 (1992)

32. K.K. Innes, I.G. Ross, W.R. Moomaw, J. Mol. Spectrosc. 132, 492 (1988)

33. M. Riese, Z. Altug, J. Grotemeyer, Phys. Chem. Chem. Phys. 8, 4441 (2006)

34. S. Tixier, G. Cooper, R. Feng, C. Brion, J. Electron Spectrosc. Relat. Phenom. 123, 185 (2002)

Open Access This is an open access article distributed under the terms of the Creative Commons Attribution License (http://creativecommons.org/licenses/by/4.0), which permits unrestricted use, distribution, and reproduction in any medium, provided the original work is properly cited. 